\title{
Assessment of Drinking Water Quality of Madhyapur- Thimi and Study of Antibiotic Sensitivity against Bacterial Isolates
}

\author{
Bina Laxmi Jayana ${ }^{1}$, Tista Prasai ${ }^{2}$, Anjana Singh ${ }^{3}$ and Kayo Devi Yami ${ }^{2}$ \\ ${ }^{1,3}$ Central Department of Microbiology Tribhuvan University, Kathmandu \\ ${ }^{2}$ Nepal Academy of Science and Technology Khumaltar, Lalitpur
}

\begin{abstract}
The study was undertaken to assess the existing status of drinking water quality of Madhyapur-Thimi. A total of 105 water samples comprising $50(47.61 \%)$ wells, $45(42.82 \%)$ tap water and $10(9.52 \%)$ stone spouts were randomly collected. The physicochemical and microbiological parameters were analyzed following standard technique. The $\mathrm{pH}$ $(1.9 \%)$, conductivity $(34.28 \%)$ and turbidity $(16.19 \%)$ of water samples had crossed the permissible guideline values as prescribed by WHO and national standard. All samples contained nitrate values within the WHO permissible value as well as national standard but hardness (2\%), chloride (2.85\%), iron (26.66\%), ammonia (11.42\%), and arsenic content $(1.90 \%)$ crossed the WHO guideline value but none of the water samples crossed the national standard for arsenic. Arsenic having $0.025 \mathrm{mg} / 1(25 \mathrm{ppb})$ was detected from two well water samples, Makanani well and Ajimanani well. Total coliform count showed $64.76 \%$ of samples crossed the WHO guideline values. Eleven different kinds of enteric bacteria were isolated from different sources, Enterobacter spp. being the predominant. Isolates were subjected for antibiotic susceptibility pattern using ten antibiotics. Among total isolates, resistance was directed to $79.5 \%$ Erythromycin, 62.67\% Penicillin G, 61.9\% Amoxycillin, 34.5\% Ampicillin, 21.1\% Tetracycline, 15.4\% Ceftriaxone, 14.7\% Amikacin, 14.7\% Cephotaxine, 5.6\% Chlorophenical and 5.6\% Ofloxacin respectively.
\end{abstract}

Key words: coliform, enteric bacteria, permissible value, physicochemical, antibiotic resistance

\section{Introduction}

Water has a profound influence on human health and quality of the water supplied is important in determining the health of individuals and whole communities. Safe water quality is a major concern with reference to public health importance as health and well being of the human race is closely tied up with the quality of water used (Sharma et al. 2005).

Despite major efforts to deliver safe piped, community water to the world's population, the reality is that water supplies delivering safe water will not be available to all people in the near term (Agarwal 1981). The growing imbalances between supply and demand have resulted in pollution and environmental degradation. As a consequence of such unhygienic water quality condition, water borne diseases such as diarrhoea, dysentery, cholera, and gastroenteritis occur often. These diseases are prevalent in both urban and rural areas throughout the kingdom. Diseases caused by contaminated water are among the ten most prevalent water borne diseases in Nepal (DoHS 1998). Thousands of people die or suffer from water and sanitation related diseases. Water, therefore, the most vital resource for all kinds of life on this planet, can be extremely dangerous when it becomes the vehicle of transmission of diseases (Sharma 2000).

Water-borne diseases are among the most recent emerging and re-emerging infectious diseases, which 
have recently proven to be the biggest health threat worldwide and they contribute between $70-80 \%$ of health problems in developing countries. These diseases continue to be a major cause of human mortality and morbidity. Diarrhoeal diseases remain a leading cause of illness and death in the developing world which alone causes 2.2 million of the 3.4 million water related deaths per year, $90 \%$ of these deaths involve children less than five years of age. In Nepal, every year, 30-40 thousand people die from this disease. In 2003/04, total diarrheoal visits were 787,094 and total diarrhoeal deaths were 194. The incidence of diarrhoea in children under five years were $222 / 1000$ population and case fatality rate were 0.2/1000 population ( $\mathrm{MoH} 2003 / 04)$.

This common type of health risk can be treated by using antibiotic therapy which is a modern issue. The emergence of antibiotic resistant (AR) bacteria has become a growing public health concern in recent years. The presence and persistence of AR bacteria, particularly multiple-antibiotic resistant (MAR) bacteria is a serious threat to mankind. Antibiotic susceptibility testing is an essential component of the practice. It allows physicians to make accurate choices with all forms of antimicrobial therapy. Without surveillance for the development of antibiotic resistance, serious infections may lead to death due to inadequate antibiotic therapy (Patersen 2006).

\section{Methodology}

The study was conducted in Madhyapur -Thimi from October 2005 to November 2006. One hundred and five water samples were randomly collected from different sources. Physicochemical and microbiological analyses were done following (APHA 1998) for the assessment of drinking water quality. Temperature and $\mathrm{pH}$ of water samples were recorded at the site during sampling period. Other parameters were analyzed at the Environment Laboratory of NAST. The samples were analyzed on the same day immediately after its delivery. When immediate analyses were not possible, the samples were preserved at $4^{\circ} \mathrm{C}$.

Total coliforms were enumerated by the membrane filtration (MF) technique as described by (APHA 1998). The enrichment of the samples were done in Selenite F broth follows by the culture on Xylose Lysine Deoxlcholate (XLD) agar for the detection of Salmonella spp. and Shigella spp. Similarly, for Vibrio cholerae enrichment in alkaline peptone water and culture on TCBS agar were done. All isolated colonies were streak on nutrient agar to get pure colonies. Bacterial isolates were identified on the basis of their cultural, morphological and biochemical tests. Test parameters, methods of analyses and instruments used for analyses are tabulated as follows:

Table 1. Test parameters, methods of analyses and instruments used

\begin{tabular}{|c|c|c|c|c|}
\hline S.N & Parameters & Unit & Methods of analyses & Instrument/Kit \\
\hline & Physicochemical & & & \\
\hline $\begin{array}{l}1 \\
2 \\
3 \\
4 \\
5 \\
6 \\
7 \\
8 \\
9\end{array}$ & $\begin{array}{l}\text { pH } \\
\text { Conductivity } \\
\text { Turbidity } \\
\text { Hardness } \\
\text { Chloride } \\
\text { Iron } \\
\text { Ammonia } \\
\text { Nitrate } \\
\text { Arsenic } \\
\text { Bacteriological }\end{array}$ & $\begin{array}{l}- \\
\mu \mathrm{s} / \mathrm{cm} \\
\mathrm{NTU} \\
\mathrm{mg} / 1 \\
\mathrm{mg} / 1 \\
\mathrm{mg} / 1 \\
\mathrm{mg} / 1 \\
\mathrm{mg} / 1 \\
\mathrm{mg} / \mathrm{l}\end{array}$ & $\begin{array}{l}\mathrm{pH} \text { meter } \\
\text { Conductivity meter } \\
\text { Turbidimeter } \\
\text { EDTA titrimetric method } \\
\text { Argentometric method } \\
\text { Phenanthroline method } \\
\text { Kit method } \\
\text { Kit method } \\
\text { Kit method }\end{array}$ & $\begin{array}{l}\text { Toa Electronics, Japan } \\
\text { Conductivitymeter LF } 91 \\
\text { Nephelometer, Elico India } \\
\text { - } \\
\text { - } \\
\text { Colorimeter } \\
\text { Machegery Nagal test kit } \\
\text { Machegery Nagal test kit } \\
\text { Machegery Nagal test kit }\end{array}$ \\
\hline 10 & Total Coliform & $\mathrm{Cfu} / 100$ & Membrane Filtration (MF) & Millipore Membrane Filter \\
\hline
\end{tabular}

Antibiotic sensitivity pattern of isolated bacteria was assayed using a modified Kirby-Bauer disk diffusion method (Bauer et al. 1966). Organisms were classified as sensitive or resistant to an antibiotic according to the diameter of the inhibition zone surrounding each antibiotic disk as listed by manufacturer.

\section{Results Water quality assessment}

Out of 105 water samples analyzed, $\mathrm{pH}(1.9 \%)$, conductivity $(34.28 \%)$, turbidity $(16.19 \%)$ of samples crossed the permissible guideline values as prescribed by (WHO 2007) and national standard. All samples contained nitrate 
values within the WHO permissible value as well as national standard but hardness $(2 \%)$, chloride $(2.85 \%)$, iron $(26.66 \%)$, ammonia (11.42\%), and arsenic content $(1.90 \%)$ crossed the WHO guideline values but none of the water samples crossed the national standard for arsenic. Arsenic at $0.025 \mathrm{mg} / 1$ (25ppb) was detected from two well water samples, Makanani well and Ajimanani well. These results have been presented in Table 2 .

Table 2. Number of water samples above and below the WHO guideline values

\begin{tabular}{l|c|c|c|c|c|c|c|c}
\hline Parameters & \multicolumn{2}{|c|}{ Within WHO guideline } & \multicolumn{2}{c|}{ Total } & \multicolumn{2}{c|}{ Above WHO guideline } & Total \\
\hline & Well & Tap & Stonespout & & Well & Tap & Stonespout & \\
\hline $\mathrm{pH}$ & 39 & 42 & 8 & 89 & 2 & 0 & 0 & 2 \\
Conductivity & 21 & 40 & 8 & 69 & 29 & 5 & 2 & 36 \\
Turbidity & 43 & 38 & 7 & 88 & 7 & 7 & 3 & 17 \\
Hardness & 49 & 45 & 10 & 104 & 1 & 0 & 0 & 1 \\
Chloride & 47 & 45 & 10 & 102 & 3 & 0 & 0 & 3 \\
Iron & 33 & 37 & 7 & 77 & 17 & 8 & 3 & 28 \\
Ammonia & 43 & 41 & 9 & 93 & 7 & 4 & 1 & 12 \\
Nitrate & 50 & 45 & 10 & 105 & 0 & 0 & 0 & 0 \\
Arsenic & 48 & 45 & 10 & 103 & 2 & 0 & 0 & 2 \\
\hline
\end{tabular}

Total coliform count showed $64.76 \%$ of samples crossed the WHO guideline values. Well water and stone spout contained high numbers of coliforms (96\% and $80 \%$ respectively) followed by tap water samples in which only $28.88 \%$ water samples contained coliform (Fig.1).

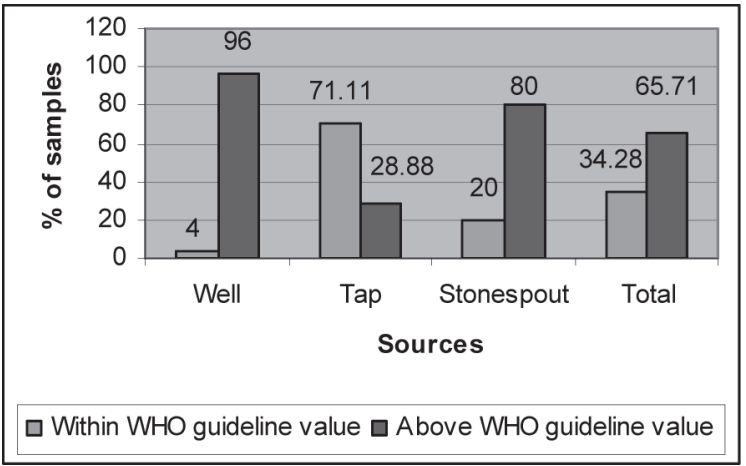

Fig.1. Source wise quality of coliform count

A total of 142 enteric bacteria of 11 different types were isolated. Sourcewise distribution revealed that 106 (74.64\%), $11(7.74 \%)$, and $25(17.6 \%)$ of isolates from well, tap and stonespout water samples respectively. The organisms identified include Escherichia coli, Enterobacter spp., Citrobacter spp., Klebsiella spp., $P$. vulgaries, P mirabilis., Pseudomonas aeruginosa, $S$. Typhi, S. Paratyphi, Shigella dysentery, and Vibrio cholerae. Percentage of Enterobacter spp. (29.5\%) was found to be maximum followed by E. coli $(24.6 \%)$, Citrobacter spp (20.4\%), P. vulgaris (7.0\%), Klebsiella spp. (5.6\%), P. mirabilis (3.5\%), S. dysentery (2.8\%), S. Typhi (2.1\%), Pseudomonas aeruginosa (2.1\%), Salmonella paratyphi $(1.4 \%)$, and $V$. cholerae $(0.7 \%)$ (Fig. 2).

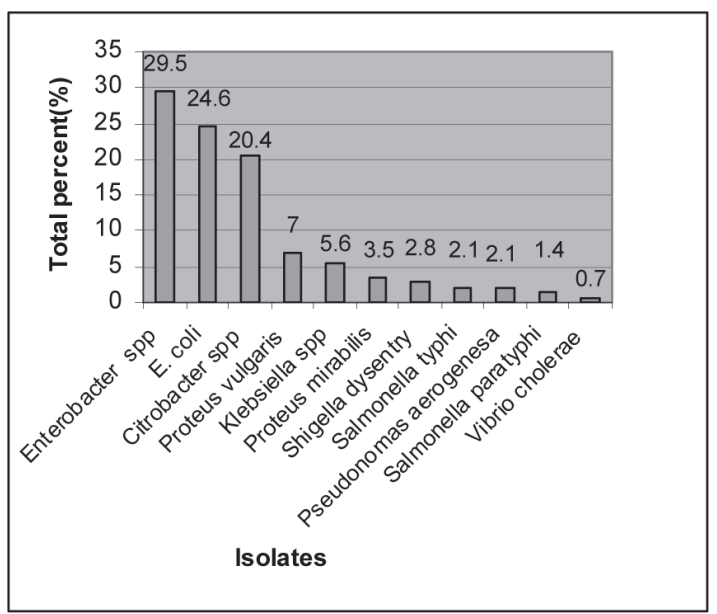

Fig. 2. Status of different bacterial isolates (\%)

Isolates were subjected for antibiotic susceptibility pattern using ten antibiotics. Among total isolates, resistance was directed to $79.5 \%$ Erythomycin, 62.67\% Penicillin G, 61.9\% Amoxycillin, 34.5\% Ampicillin, $21.1 \%$ Tetracycline, $15.4 \%$ Ceftriaxone, $14.7 \%$ Amikacin, 14.7\% Cephotaxine, 5.6\% Chloramphenicol, 5.6\% Ofloxacin respectively. 
Nepal Journal of Science and Technology 10 (2009) 167-172

Table 3. Antibiotic sensitivity pattern shown by different isolates

\begin{tabular}{|c|c|c|c|}
\hline S.N & Antibiotics & $\%$ Resistant & $\%$ Sensitive \\
\hline 1 & Ampicillin (Amp 10 $\mu \mathrm{g})$ & 34.5 & 40.8 \\
\hline 2 & Erythomycin (E $15 \mu \mathrm{g})$ & 79.5 & 0 \\
\hline 3 & Penicillin G (P 10 $\mu \mathrm{g})$ & 62.7 & 7.7 \\
\hline 4 & Ofloxacin (Ofx $5 \mu \mathrm{g})$ & 5.6 & 92.9 \\
\hline 5 & Chloramphenicol $(\mathrm{C} 30 \mu \mathrm{g})$ & 5.6 & 42.9 \\
\hline 6 & Amoxicillin (Am 30 $\mu \mathrm{g})$ & 61.9 & 6.3 \\
\hline 7 & Cephotaxime (Ce $30 \mu \mathrm{g})$ & 14.7 & 85.2 \\
\hline 8 & Amikacin $(\mathrm{Ak} 30 \mu \mathrm{g})$ & 14.7 & 85.2 \\
\hline 9 & Ceftriaxone (Ci 30 $\mu \mathrm{g})$ & 15.4 & 84.5 \\
\hline 10 & Tetracycline $(\mathrm{T} 30 \mu \mathrm{g})$ & 21.1 & 49.2 \\
\hline
\end{tabular}

\section{Discussion}

Quality of water consumed is critical in controlling infectious diseases and other health problems. Water quality can be ensured through regular monitoring. A regular monitoring of water not only prevents diseases and hazards but also checks the water resource from going further pollution.

Physico-chemical and microbiological parameters were analyzed to identify the physical status, impurities, other dissolved substances and microorganisms that affect water used for domestic purposes. The study revealed that $13.33 \%$ samples showed the $\mathrm{pH}$ values below the permissible guideline values as prescribed by $\mathrm{WHO}$ and national standard. In drinking water, acidic $\mathrm{pH}$ may cause corrosion of metal pipes in the distribution system and alkaline $\mathrm{pH}$ adversely affect the disinfection process.

The result showed that the conductivity of $34.28 \%$ samples crossed the permissible guideline value as prescribed by WHO and national standard. The studies carried out so far do not reveal direct health affect however, high conductivity most of the time indicate addition of some pollutants to it. Out of total, $16.19 \%$ of samples had crossed the permissible limit for turbidity. Similar result was detected by (Prasai 2007) as $21 \%$ of tested samples crossed the WHO guideline. Turbidity indicates clarity of water and is caused by the presence of suspended and colloidal matter. Usually, water with high turbidity has offensive appearance, colour, taste and odor. Turbidity also correlates with iron content of water samples. Turbidity in natural water is caused by clay, silt, organic matter, phytoplankton and other microscopic organisms.
Hardness of most water samples (99.04\%) were found within the acceptable limit proposed by WHO guideline value, only one sample from well, Chhea well contained hardness above the WHO Guideline value and was found to be $616 \mathrm{mg} / \mathrm{l}$. Hardness in water is due to dissolved calcium and to a lesser extent, magnesium. Sewage and industrial wastes are important sources of calcium and magnesium. The main impact of hardness on scale deposition and scum formation as well as consumption of more soap to produce lather.

Only three $(2.85 \%)$ water samples exceeded the WHO recommended value for chloride. Similar result was recorded by (Maharjan 1998). Chloride in drinking water originates from natural sources, sewage and industrial effluents, urban runoff containing de-ionising salts and saline intrusion. High concentration of chloride gives a salty taste to water and beverages. Excessive chloride concentrations increase rate of corrosion of metals in the distribution system, depending on the alkalinity of water.

Overall 77 (73.33\%) water samples showed iron content within WHO guideline value while 28 (26.66\%) samples crossed this guideline value. Iron in drinking water is more significant in its aesthetic and taste value rather than in health aspects. High concentration of iron in water stains laundry, sanitary ware, gives an undesirable taste and develops turbidity as well. Iron also promotes the growth of "iron bacteria", which derive their energy from the oxidation of ferrous iron to ferric iron and in the process deposits a slimy coating on the piping.

The concentration of total ammonia ranged from fairly low to extremely high, exceeding the maximum 
allowable limit. Of total, 93 (88.57\%) samples were found within the WHO permissible limit and 12 (11.42\%) exceeded the allowable limit for ammonia content in drinking water. Ammonia in water is an indicator of possible bacterial, sewage and animal waste pollution. Anaerobic groundwater may contain higher level of ammonia than natural level ground and surface water due to intercalated layers of peat and lignite. Ammonia content in water may be harmful to health since it can be converted to nitrate. The toxicity of ammonia increases with $\mathrm{pH}$ because at higher $\mathrm{pH}$ most of the ammonia remains in the gaseous form.

A study (Anonymous 1999) showed that all the wells of Madhyapur- Thimi contained high amount of nitrate but in the present study, all the tested water samples contained nitrate within the WHO permissible value. Most samples contained $0 \mathrm{mg} / \mathrm{l}$ nitrate while some samples contained maximum up to $50 \mathrm{mg} / \mathrm{l}$ as in Lokanthali well water sample. Nitrate in drinking water is the indicator of organic pollution. Nitrate can be added to water from industrial effluents, agricultural and domestic wastes. Nitrate itself is not toxic to humans but the effects are hazardous when it is converted to nitrite by microbial action. The high concentration of nitrate if reported as nitrate-nitrogen is of health significance to pregnant women and infants under 6 months. It leads to disease in infants known as Blue baby syndrome. This disease can even lead to death, as a result of prolonged consumption of nitrate rich water.

Presence of arsenic is one of the emerging problems in drinking water as it may cause cancer and skin lesions. Arsenic concentrations of $265 \mathrm{ppb}$, $250 \mathrm{ppb}$ and $212 \mathrm{ppb}$ were detected in Kuleshwore, Harihar bhawan and in Balkhu area respectively (ENPHO 2005). In the present study arsenic was not detected in water samples from tap water and stone spouts. However, arsenic content $0.025 \mathrm{mg} / 1$ ( $25 \mathrm{ppb}$ ) was detected from two well water samples, Makanani well and Ajimanani well. Arsenic is introduced into drinking water sources primarily by dissolution of naturally occurring minerals, ores, industrial effluents, and atmospheric deposition, concentrations in ground water in some areas are sometimes elevated as a result of erosion from natural sources. Severe poisoning can arise from the ingestion of as little as $100 \mathrm{mg}$ arsenic trioxide; chronic effect may result from the accumulation of arsenic compound in the body at low intake levels.
In this study, almost all water samples from wells and stone spouts contained coliforms whereas only 13 tap water samples contained them. Similarly result was obtained by (Shrestha 2008) and (Prasai 2007). Sourcewise distribution of coliform count clearly showed that the samples from well water $2(4.0 \%)$, tap water $32(71.11 \%)$ and stone spout $2(20 \%)$ were within the WHO guideline value while well water $48(96.0 \%)$, tap water $13(28.88 \%)$ and stone spout $8(80.0 \%)$ crossed WHO guideline value. The results clearly showed that most of the wells and stone spouts had microbial contamination indicating that the loads of coliform bacteria in natural water sources were higher than the WHO guideline value. One hundred forty two bacteria were isolated from different water samples comprising 11 different types. Almost all natural water sources such as wells and stone spouts were found to be microbiologically contaminated due to infiltration of various kinds of pollutants, toxic wastes from chemical plants, biological wastes from hospitals resulting in plumes of pollutants traveling in the groundwater and contaminating the underground environment. Domestic wastewater, industrial waste, increase in use of agrochemicals and hazardous waste disposal sites add ground water contamination. These natural sources were neither treated nor protected properly.

Some of tap water samples were found to be unsatisfactory as they contained coliforms. This may be due to the failure of disinfection of raw water at treatment plants or lack of well managed pipe lines and the infiltration of contaminated sewage through cross connection, leakage points and back siphonage. In piped supplies, discontinuity increases the likelihood of contamination as the risk of back siphonage into the distribution network is increased when pipes are at lower pressure than the surrounding soil, which often contains leaked out effluent from leaking sewers.

A total of 142 isolates were assayed against ten antibiotics. Resistance was found most commonly directed toward Erythomycin (79.5\%) and penicillin G $(62.67 \%)$. All the isolates were resistant to at least one antibiotic. $P$ aeruginosa was found resistant to almost all antibiotics tested. (Shrestha 2002) also reported similar antibiotic sensitivity pattern as $74.07 \%$ isolates were found to be resistant to at least one antibiotic and MAR was found in $3.07 \%$ of the total isolates. Antibiotics are used to counteract bacterial infections, but extensive use and misuse of antimicrobial drugs have favoured the emergence of resistant strains. 
Repeated exposure of bacteria to antibiotics may lead to the development of resistant bacterial strains. Production of enzymes which inactivate or modify antibiotics and changes in the bacterial cell membrane, preventing the uptake of an antimicrobial also leads to resistant strains. Serious infections may lead to death due to inadequate antibiotic therapy. The increasing ineffectiveness of drugs combined with the unavailability of alternative antimicrobials can contribute to the spread of major infectious diseases causing serious epidemics. So, antibiotics susceptibility test is a crucial for accurate choices of antimicrobial therapy.

The study clearly explored that most of the wells and stone spouts of Madhyapur- Thimi were found microbially contaminated as $64.76 \%$ of the samples crossed the WHO guideline value and 142 bacteria were isolated from different sources indicating that the load of coliform bacteria in natural water sources were higher. Besides coliforms, some of the sources of Madhyapur-Thimi were contaminated with chemical pollutants such as iron, arsenic and ammonia indicating that acute effects may be encountered where major pollution events has occurred or where levels of certain chemicals are high. Informing that deteriorating water quality may contribute different types of water-borne diseases at any time, quality of water consumption is critical in controlling infectious diseases and the level of diseases can be decreased significantly by implementing simple strategies, such as proper waste and water management and education on maintenance of hygienic conditions.

\section{Acknowledgement}

The authors would like to express profound gratitude to Nepal Academy of Science and Technology (NAST) for providing laboratory and other facilities.

\section{References}

Agarwal, A. 1981. Water, sanitation, health-for all. Center for international Development \& Invironment, London 146 pp.
APHA. 1998. Standard methods for the examination of water and wastewater. (20 ${ }^{\text {th }}$ edition). American Public Health Association, Washington, DC.

Bauer, A.W., W.M.M. Kirby and J.C. Sherris. 1966. Antibiotic susceptibility testing by standardized dingle disc method. American Journal of Clinical Pathology 45:493-496.

DoHS. Annual Report-1997/98. Ministry of Health and Population, Department of Health Services, Kathmandu, Nepal.

ENPHO. 2005. Arsenic vulnerability in ground water resources in Kathmandu valley (Final Report). Environment and Public Health Organization. A joint study conducted by JiCA Exper Office at MPPW and ENPHO, Kathmandu. 24 pp.

Maharjan, M. 1998. Assessment of groundwater quality and study of antibiotic resistance and oligodyanamic action against some isolated enteric bacteria. M.Sc. dessertation. Central Department of Microbiology. Tribhuvan University, Kathmandu, Nepal.

MoH. Annual report-2003/2004. Ministry of Health, Kathmandu.

Patersen, D. 2006. The importance of antibiotic susceptibility testing. Antibiotic Management Program. University of Pitterburg Medical Centre, USA.

Prasai, T., D.R. Joshi, B.Lekhak and M.P. Baral. 2007. Microbiological analysis of drinking water of Kathmandu valley. Scientific World 5:112-114.

Anonymous.1999. Environment workbook of MadhyapurThimi Municipality, Bhaktapur. Sharma, A. 2000. Water pollution and its impact on health: Nepalese context. Central Department of Microbiology, Tribhuvan University, Kirtipur. pp. 1-3.

Sharma, S., R. Bajracharya, B.K. Sitaula and J. Merg . 2005. Water quality in the Central Himilaya, Current Science 89(5):782.

Shrestha, S. 2002. Assessment of drinking water quality supplied by Nepal Water Supply Corporation Sundarighat and identification, antibiotic sensitivity pattern and serotyping of isolated Escherichia coli. M.sc dissertation. Central Department of Microbiology, Tribhuvan University, Kirtipur, Kathmandu, Nepal.

Shrestha, S. 2008. Water quality assessment of public wells of Madhyapur-Thimi Municipality. M.Sc. dissertation. Central Department of Environmental Science, Tribhuvan University, Kathmandu.

WHO. 2007. Health through safe drinking water and basic sanitation. World Health Organization, Geneva. 